\title{
Urachal abscess in a child with single kidney and multiple anomalous vertebrae-a case report and literature review
}

\author{
Mohamad K. Abou Chaar ${ }^{1 *}$ (D), Tamador Al-Shamaileh² and Mohammad M. Saleem²
}

\begin{abstract}
Background: Urachal anomalies (UAs) are rare in children; the most encountered are urachal cysts, urachal sinus, and urachal diverticulum. Other associated anomalies have been reported to include renal and abdominal wall defects. No skeletal anomalies have been reported to date.

Case presentation: We present a case of a 20-month-old female patient, who presented to our emergency department with a fever of 2 weeks duration associated with colicky abdominal pain, a tender abdomen, and an infraumbilical mass. The suspicion of urachal sinus abscess was confirmed by ultrasound. The patient was also found to have a single left kidney and multiple vertebral segmental anomalies on a full-body computed tomography scan. The patient underwent open surgical excision of the urachal abscess without complications on follow-up.

Conclusion: Urachal abscess is rare in children. Associated anomalies include renal and abdominal wall defects. To our knowledge and based on our meticulous search through the literature, this is the first case to report a combination of renal and skeletal findings in a child. Whenever a urachal remnant is found in a patient, a radiological investigation should be made to rule out associated anomalies.
\end{abstract}

Keywords: Urachus, Urachal abscess, Single kidney, Vertebral anomaly

\section{Background}

The urachus is a structure that results from the involution of the allantois and the urogenital sinus during gestation. Failure of complete obliteration of those embryonic structures is rare and leads to four types of urachal abnormalities: patent urachus, umbilical-urachal sinus, urachal cyst, and vesicourachal diverticulum [1].

Urachal cysts form when both the visceral and the umbilical ends of the lumen fuse, but the midportion remains filled with fluid. While the cysts asymptomatic, they may become infected, presenting as a palpable large

\footnotetext{
* Correspondence: ma.12564@khcc.jo

'Department of Surgery, King Hussein Cancer Center, Queen Rania Al

Abdulla St, Amman 11941, Jordan

Full list of author information is available at the end of the article
}

mass or as an abscess [2]. Here, we report a case of a patient with a urachal abscess presented with fever and paraumbilical mass, which was successfully managed with surgical excision.

\section{Case presentation}

A 20-month-old female patient presented with fever of $39{ }^{\circ} \mathrm{C}$ and recurrent attacks of colicky abdominal pain lasting for a few minutes with no other associated symptoms as reported by the mother. Physical examination revealed fullness in the umbilical region.

Laboratory investigations showed leukocytosis (22,000/ $\mathrm{mm} 3)$, elevated lactate dehydrogenase (1036 IU/L) and unremarkable hemoglobin, coagulation profile, urine analysis, and cultures. Work up for brucellosis, typhoid

\section{Springer Open}

(c) The Author(s). 2020 Open Access This article is licensed under a Creative Commons Attribution 4.0 International License, which permits use, sharing, adaptation, distribution and reproduction in any medium or format, as long as you give appropriate credit to the original author(s) and the source, provide a link to the Creative Commons licence, and indicate if changes were made. The images or other third party material in this article are included in the article's Creative Commons licence, unless indicated otherwise in a credit line to the material. If material is not included in the article's Creative Commons licence and your intended use is not permitted by statutory regulation or exceeds the permitted use, you will need to obtain permission directly from the copyright holder. To view a copy of this licence, visit http://creativecommons.org/licenses/by/4.0/. 
fever, Epstein-Barr virus, and cytomegalovirus were negative. The patient was started on empiric intravenous antibiotics without any improvement.

Abdominal ultrasound (US) showed a heterogeneous multiloculated cyst, situated immediately behind the lower anterior abdominal wall, extending from the umbilicus downward to involve the right paramedian aspect of the urinary bladder dome. The findings were suggestive of urachal remnant abscess measuring $5.5 \times 3 \times 2$ $\mathrm{cm}$. The US also showed, incidentally, a single left kidney, confirmed by a computed tomography (CT) scan; in addition, it revealed segmental butterfly anomalies of the thoracic (Figs. 1 and 2), L1, and S1 (not shown) vertebrae. The family was counseled regarding the clinical findings and the treatment options, with surgery being the optimal intervention. They were also informed about all possible complications, after which they signed an informed consent to proceed with the treatment plan.

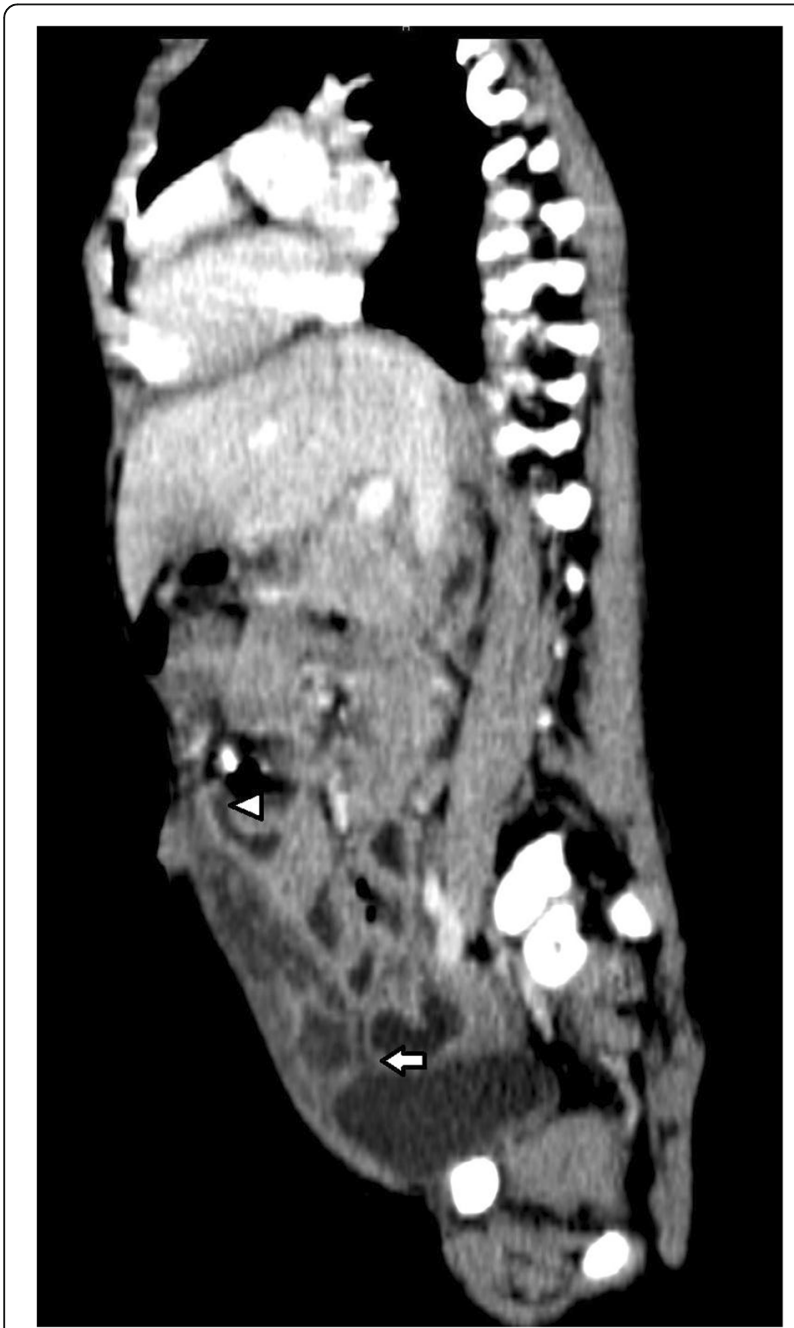

Fig. 1 Sagittal view of the abdominal CT showing multiloculated urachal abscess extending from the bladder dome (arrow) to the umbilicus (arrow head)
Open surgical complete excision of the urachal abscess was done (Fig. 3). The histopathology report confirmed the diagnosis of inflamed patent urachus with abscess formation and no evidence of malignancy. The patient was discharged home 3 days postoperatively. Follow-up continued for 3 months with no recurrence. The parents provided informed consent for the data concerning the case to be submitted for publication.

\section{Discussion}

The urachus, also known as the median umbilical ligament, is a midline extraperitoneal tubular structure extending from the dome of the bladder to the umbilicus, bordered by the transversalis fascia anteriorly and the parietal peritoneum posteriorly [3]. Failure to involute in utero results in UAs which are seen in 2/300,000 pediatric admissions [4] with reported cases of urachal cysts, since 1882, being fewer than 200 cases among adults [5]. They are more common in males (2:1) with $10-48 \%$ for patent urachus, $31-43 \%$ for urachal cyst, $18-43 \%$ for urachal sinus, and $3-4 \%$ for urachal diverticulum $[6,7]$.

Urachal cysts are usually asymptomatic, unless they are large enough to cause compression symptoms, complicated by infection, rupture, or malignant transformation [8]. They present with abdominal pain, fever, lethargy, umbilical discharge, or a midline mass [5] which might drain into the urinary bladder or through the umbilicus, leading to fistula formation [9]. In complicated cases, it may lead to necrotizing fasciitis [5] or rupture inside the abdomen, causing peritonitis and sepsis [9].

Urachal remnant has been associated with other anomalies including hypospadia, meatal stenosis, vesicouretheral reflux, ureteropelvic obstruction, crossed renal ectopia, umbilical and/or inguinal hernias, cryptorchidism, anal atresia, and omphalocele as reported in the literature [10-13]. Bertozzi et al. reported inguinal hernia in 12 children that were treated between 2005 and 2013, as the most common associated anomaly (33\%) [14].

UAs can be diagnosed by US. Two studies reported 12 and 27 cases of UA, in which all of their patients were diagnosed by US with limited usage of CT scans and magnetic resonance imaging (MRI) which were only used for further detailed anatomy [14, 15]. However, Widni et al. reported US as having 79\% sensitivity, 30\% specificity, and $83 \%$ positive predictive value in diagnosing UAs [16].

Yu et al. reported that many of the features of UA, including congenital lesions with or without superimposed infection and tumors, are well displayed at sagittal US with a CT scan to help confirm the US findings and 

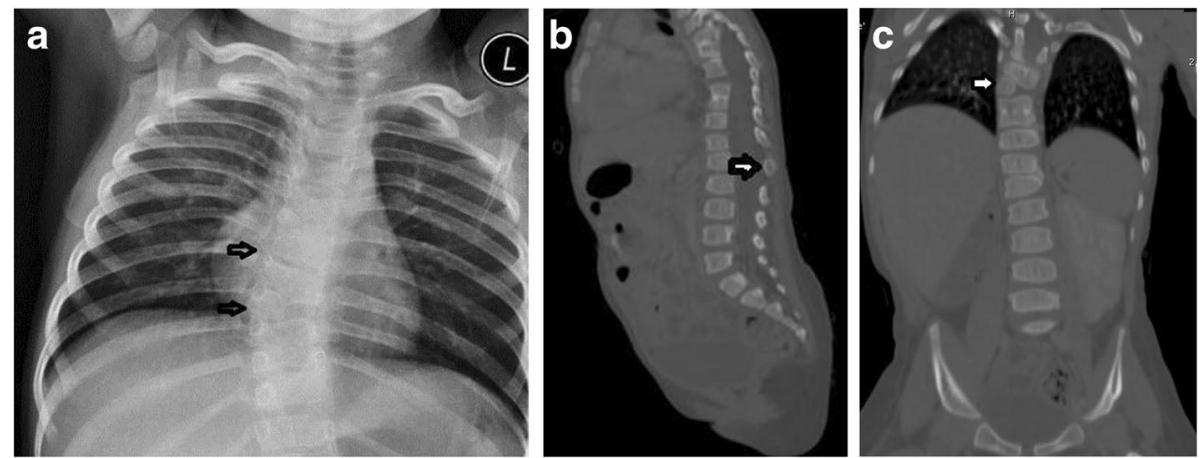

Fig. 2 a Posterior-anterior chest X-ray showing thoracic vertebral anomalies. b and c Sagittal and coronal chest, abdomen, and pelvis CT scan showing vertebral anomalies non-visualization of the right kidney

disclose the nature and local extension of the disease as well as any systemic metastases [1].

Complete surgical excision is considered the treatment of choice, given the risk of malignant transformation and the high recurrence rate after simple drainage, which Mesrobian et al. reported at 39\% [17]. The excision can be done either by an open laparoscopic approach [14, 15] or a robotic assisted laparoscopic surgery [18]. Bertozzi et al. reported 12 cases of UA that were treated by laparoscopic or laparoscopic-assisted surgery [14]. Sato et al. reported 13 patients treated by the umbilical approach and 7 patients treated by the laparoscopic approach. There was no difference between the 2 groups in operative time or hospital stay [15]. Excision can be done safely using robotic-assisted laparoscopic surgery with short hospitalization and minimum to no narcotic pain control postoperatively [18].

It should be noted that Galati et al. reported that urachal remnants in patients younger than 6 months are likely to be resolved without operative management [6]. Sato et al. recommended conservative follow-up for UA patients who are under 1 year of age unless there are repeated infections [15].

In this case, our patient had non-resolving symptoms even with empirical antibiotic treatment, and the patient

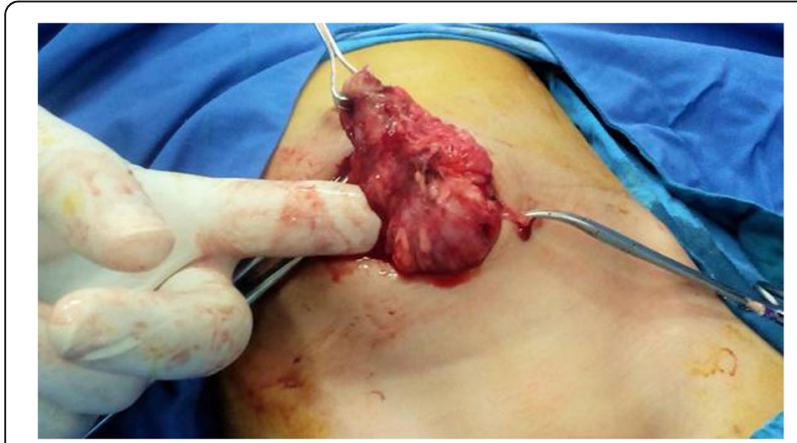

Fig. 3 Open surgical excision of urachal abscess was later found to have associated anomalies including a single kidney and multiple vertebral anomalies. Based on our literature review, no case has been reported to date that includes the associated anomalies.

\section{Conclusion}

Urachal abscess is a rare diagnosis that can present with nonspecific abdominal pain or fever and may lead to potentially serious complications including peritonitis, in case of perforation, and sepsis. US is considered the first diagnostic imaging method, followed by CT and MRI which can be used for detailed anatomy and to rule out any associated anomalies. Treatment of choice is complete surgical excision, if conservative management fails, either by open or laparoscopic methods.

\section{Abbreviations \\ US: Ultrasound; CT: Computed tomography; UC: Urachal cyst; UR: Urachal remnant; UA: Urachal anomaly; MRI: Magnetic resonance imaging}

\section{Acknowledgements}

Not applicable

\section{Authors' contributions}

MK performed the literature search guided by MS. He also wrote the manuscript. MS and TA oversaw the manuscript inception, guided the literature search, counseled the patient, wrote portions of the manuscript, and provided major revisions. All authors read and approved the final manuscript.

\section{Funding}

Not applicable

Availability of data and materials

Available upon request.

Ethics approval and consent to participate

Not applicable

Consent for publication

Consent was obtained from the patient's parent.

Competing interests Not applicable 


\section{Author details}

'Department of Surgery, King Hussein Cancer Center, Queen Rania Al Abdulla St, Amman 11941, Jordan. ${ }^{2}$ Department of Pediatric Surgery, Jordan University Hospital, Amman, Jordan.

Received: 22 November 2019 Accepted: 15 May 2020

Published online: 18 June 2020

\section{References}

1. Yu J, Kim K, Lee H, Lee Y, Yoon C, Kim M. Urachal remnant diseases: spectrum of CT and US findings. RadioGraphics. 2001;21:451-61.

2. Berrocal T, López-Pereira P, Arjonilla A, Gutiérrez J. Anomalies of the distal ureter, bladder, and urethra in children: embryologic, radiologic, and pathologic features. RadioGraphics. 2002;22:1139-64.

3. Centonze A, Salerno D, Capillo S, Mazzei A, Stranieri G. Urachal cyst abscess in an infant. J Pediatr Surg Case Rep. 2019;44:101182.

4. Sterling J, Goldsmith R. Lesions of urachus which appear in the adult. Ann Surg. 1953;137:120-8.

5. Qureshi K, Maskell D, McMillan C, Wijewardena C. An infected urachal cyst presenting as an acute abdomen - a case report. Int J Surg Case Rep. 2013; 4:633-5.

6. Galati V, Donovan B, Ramji F, Campbell J, Kropp B, Frimberger D. Management of urachal remnants in early childhood. J Urol. 2008;180:1824-7.

7. Ueno T, Hashimoto H, Yokoyama H, Ito M, Kouda K, Kanamaru H. Urachal anomalies: ultrasonography and management. J Pediatr Surg. 2003;38:1203-7.

8. El Ammari J, Ahallal Y, El Yazami AO, El Fassi M, Farih M. Urachal sinus presenting with abscess formation. ISRN Urol. 2011;2011:1-3.

9. Ilica A, Mentes O, Gur S, Kocaoglu M, Bilici A, Coban H. Abscess formation as a complication of a ruptured urachal cyst. Emerg Radiol. 2007;13:333-5.

10. Rich R, Hardy B, Filler R. Surgery for anomalies of the urachus. J Pediatr Surg. 1983; 18:370-2

11. Cilento B, Bauer S, Retik A, Peters C, Atala A. Urachal anomalies: defining the best diagnostic modality. Urology. 1998;52:120-2.

12. Suita S, Nagasaki A. Urachal remnants. Semin Pediatr Surg. 1996;5:107-15.

13. Newman B, Karp M, Jewett T, Cooney D. Advances in the management of infected urachal cysts. J Pediatr Surg. 1986;21:1051-4.

14. Bertozzi M, Riccioni S, Appignani A. Laparoscopic treatment of symptomatic urachal remnants in children. J Endourol. 2014;28:1091-6.

15. Sato H, Furuta S, Tsuji S, Kawase $H$, Kitagawa $H$. The current strategy for urachal remnants. Pediatr Surg Int. 2015;31:581-7.

16. Widni $E$, Höllwarth M, Haxhija E. The impact of preoperative ultrasound on correct diagnosis of urachal remnants in children. J Pediatr Surg. 2010;45: 1433-7.

17. Mesrobian $H$, Zacharias A, Balcom A, Cohen R. Ten years of experience with isolated urachal anomalies in children. J Urol. 1997:1316-8.

18. Rivera M, Granberg C, Tollefson M. Robotic-assisted laparoscopic surgery of urachal anomalies: a single-center experience. J Laparoendosc Adv Surg Tech. 2015;25:291-4.

\section{Publisher's Note}

Springer Nature remains neutral with regard to jurisdictional claims in published maps and institutional affiliations.

\section{Submit your manuscript to a SpringerOpen ${ }^{\circ}$ journal and benefit from:}

- Convenient online submission

- Rigorous peer review

- Open access: articles freely available online

- High visibility within the field

- Retaining the copyright to your article

Submit your next manuscript at $\boldsymbol{\nabla}$ springeropen.com 